\title{
Hard X-ray and Hot Electron Environment in Vacuum Hohlraums at NIF
}

J.W. McDonald, L.J. Suter, O.L. Landen, J.M. Foster, J.R. Celeste, J.P. Holder, E.L. Dewald, M.B. Schneider, D.E. Hinkel, R.L. Kauffman, L.J. Atherton, R.E. Bonanno, S.N. Dixit, D.C. Eder, C.A. Haynam, D.H. Kalantar, A.E. Koniges, F.D. Lee, B.J. MacGowan, K.R. Manes, D.H. Munro, J.R. Murray, M.J. Shaw, R.M. Stevenson, T.G. Parham, B.M. Van Wonterghem, R.J. Wallace, P.J. Wegner, P.K. Whitman, B.K. Young, B.A. Hammel, E.I. Moses

\section{September 29, 2005}

4th International Conference on Inertial Fusion Sciences and Applications

Biarritz, France

September 4, 2005 through September 9, 2005 
This document was prepared as an account of work sponsored by an agency of the United States Government. Neither the United States Government nor the University of California nor any of their employees, makes any warranty, express or implied, or assumes any legal liability or responsibility for the accuracy, completeness, or usefulness of any information, apparatus, product, or process disclosed, or represents that its use would not infringe privately owned rights. Reference herein to any specific commercial product, process, or service by trade name, trademark, manufacturer, or otherwise, does not necessarily constitute or imply its endorsement, recommendation, or favoring by the United States Government or the University of California. The views and opinions of authors expressed herein do not necessarily state or reflect those of the United States Government or the University of California, and shall not be used for advertising or product endorsement purposes. 
The headers will be insert by the Publisher

The headers will be insert by the Publisher

The headers will be insert by the Publisher

\title{
Hard X-ray and Hot Electron Environment in Vacuum Hohlraums at NIF
}

J.W. McDonald, L.J. Suter, O.L. Landen, J.M. Foster*, J.R. Celeste, J.P. Holder, E.L. Dewald, M.B. Schneider, D.E. Hinkel, R.L. Kauffman, L.J. Atherton, R.E. Bonanno, S.N. Dixit, D.C. Eder, C.A. Haynam D.H. Kalantar, A.E. Koniges, F.D. Lee, B.J. MacGowan, K.R. Manes, D.H. Munro, J.R. Murray, M.J. Shaw, R.M. Stevenson, T.G. Parham, B.M. Van Wonterghem, R.J. Wallace, P.J. Wegner, P.K. Whitman, B.K. Young, B.A. Hammel, and E.I. Moses

Lawrence Livermore National Laboratory P.O. Box 808, Livermore, CA 94550

*AWE, Aldermaston, United Kingdom

\begin{abstract}
Time resolved hard x-ray images $(h v>9 \mathrm{keV})$ and time integrated hard x-ray spectra $(h v=$ $18-150 \mathrm{keV}$ ) from vacuum hohlraums irradiated with four $351 \mathrm{~nm}$ wavelength NIF laser beams are presented as a function of hohlraum size and laser power and duration. The hard x-ray images and spectra provide insight into the time evolution of the hohlraum plasma filling and the production of hot electrons. The fraction of laser energy detected as hot electrons $\left(f_{\text {hot }}\right)$ and a comparison to a filling model are presented.
\end{abstract}

\section{INTRODUCTION}

High- $Z$ cavities or hohlraums are an essential part of the indirect drive approach to internal confinement fusion (ICF)[1]. These hohlraums convert intense laser light into soft $\mathrm{x}$-rays that can symmetrically implode fuel capsules or can be used for a wide variety of other high energy density experiments. The physics of laser absorption in the hohlraum must be understood to predict the hohlraum symmetry, the radiation temperatures achievable within the hohlraums and the efficiency of coupling the driver energy to the capsule. Single-ended cylindrical hohlraums ("halfraum") were used in this study, as illustrated with a computer generated image in Figure 1 a). The first 4 NIF laser beams entered the halfraum along its axis, through a Laser Entrance Hole (LEH) (bottom), striking the back wall (top), rapidly heating the Au, producing laser ablated plasma and x-rays. The x-rays in turn interact with and heat the unilluminated walls producing $\mathrm{x}$-ray ablated plasma and reemitted $\mathrm{x}$-rays. In contrast to laser-disk experiments[2], where the ablated plasma is free to expand, the hohlraum confines and accumulates the plasma[3]. As the plasma moves into the path of the incident laser beam and the hohlraum fills above $\approx 10 \%$ critical density $\left(\mathrm{n}_{\mathrm{c}}\right)$, hot electrons $(>10 \mathrm{keV})$ can be produced by laser plasma instabilities such as the stimulated Raman instability. Quantifying the hot electron production is important for ignition experiments because the hot electrons can penetrate the fuel capsule, pre-heating the fuel and thereby making it harder to compress. This paper describes measurements of plasma filling and hot electrons produced in laser heated cavities. The scaling with hohlraum size and laser power and duration are presented. The fraction of energy deposited in hot electrons, and the temperature of these electrons are shown in Figure 2. 
a

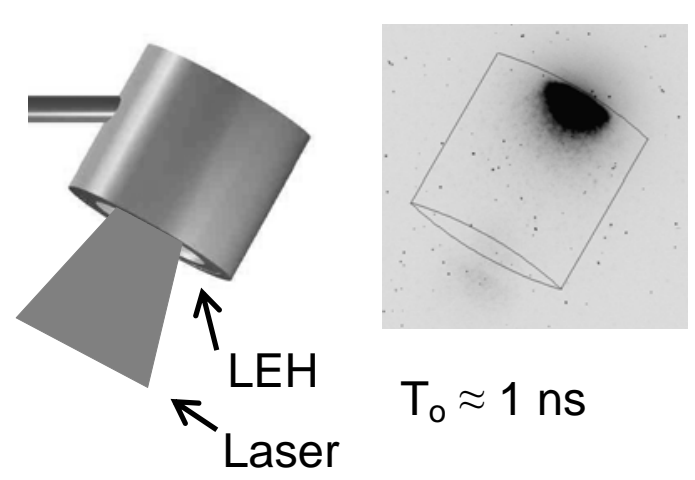

C

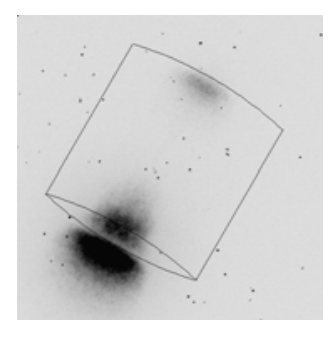

$\mathrm{T}_{\mathrm{o}}+3 \mathrm{~ns}$ d

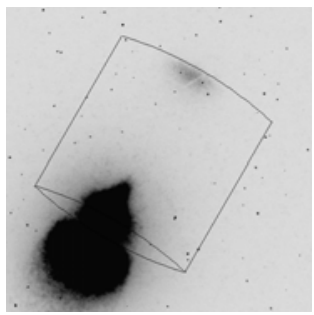

$\mathrm{T}_{\mathrm{o}}+4.5 \mathrm{~ns}$

Figure 1. a) Schematic of halfraum showing laser entering from bottom left. b-d) Thin wall hohlraum HXRI images showing progression of coronal emission from back wall to LEH. The images are negative where dark indicates more signal.

\section{EXPERIMENT}

The data presented in this paper were collected from two diagnostics during this NIF early light (NEL) experimental campaign namely; a gated flexible x-ray imager (FXI)[4] configured as a Hard X-ray Imager (HXRI) and a Filter Fluorescer Experiment (FFLEX) diagnostic[5]. The HXRI recorded time resolved hohlraum emission for $>9 \mathrm{keV}$ photons through the thin walls of the hohlraums as well as the emission of $>6 \mathrm{keV}$ photons from outside the hohlraums that passed through the $\mathrm{Al}$ filter. The FFLEX collected time-integrated, absolutely calibrated harder x-ray spectra emitted by hot electrons interacting with the gold hohlraum walls using 8 channels ranging in energy from 18 to $150 \mathrm{keV}$.

\section{RESULTS}

Figure 1 shows the HXRI view of the halfraum and three of 12 images obtained for a $13.6 \mathrm{~kJ}$ laser pulse with $6 \mathrm{~ns}$ flattop duration illuminating a $1.6 \mathrm{~mm}$ diameter halfraum equipped with an $800 \mu \mathrm{m}$ diameter LEH. From these images it can be seen that the hard x-ray emission migrates from the back wall to the LEH; this is attributed to plasma filling of the vacuum halfraum. Fig. 2a shows FFLEX spectra that are fitted to determine the temperature $(\approx 30 \mathrm{keV}$ in all cases $)$ and infer the fraction of laser energy that went into hot electrons. Fig 2a indicates a dependence between the laser intensity and the hot electron energy fraction. Also annotated in Figure 2a are features ascribed to Au-Ka and Kedge absorption.

Figure $2 \mathrm{~b}$ also shows a correlation between the hot electron fraction and the time to reach $10 \%$ critical density normalized to the laser pulse length based on an analytic plasma filling model[6.] described in more detail elsewhere $[7,8]$ 

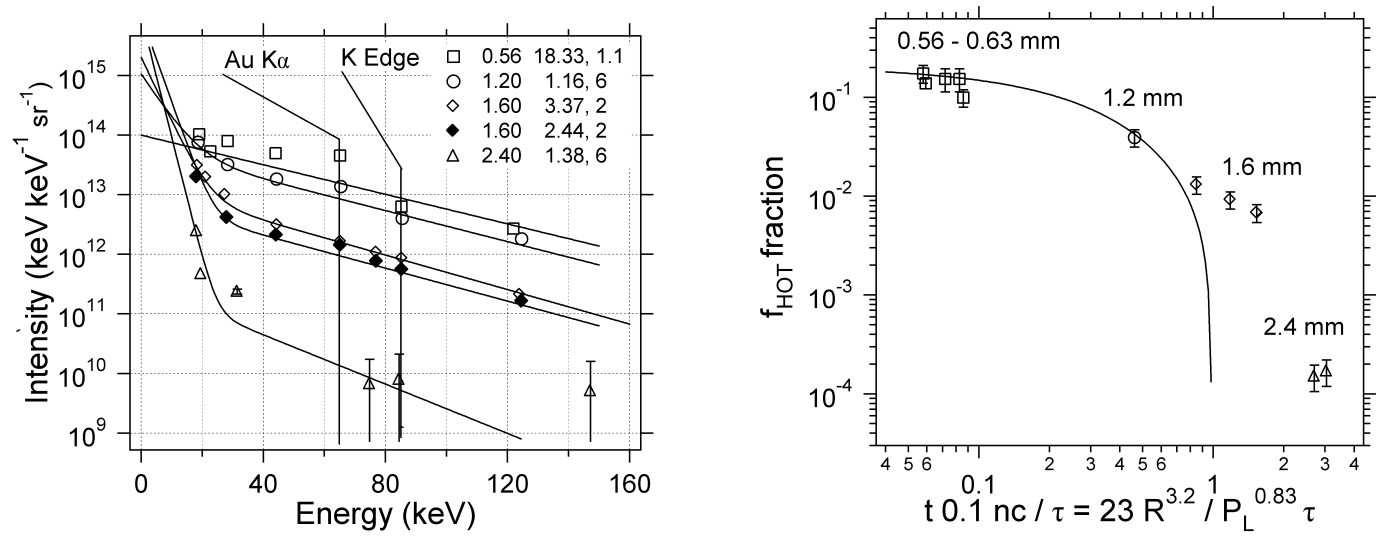

Figure 2. a) FFLEX data and fits showing Au-Ka and absorption edge. The data key is halfraum radius $\mathrm{R}$ in $(\mathrm{mm})$, laser intensity $\left(\mathrm{PW} / \mathrm{cm}^{\wedge} 2\right)$ and laser pulse length $\tau(\mathrm{ns})$. b) Fraction for various hohlraum diameters vs. fraction of time to fill to $t 0.1 \mathrm{nc}$.

\section{SUMMARY}

Time resolved hard $\mathrm{x}$-ray images and time integrated hard $\mathrm{x}$-ray spectra have provided complementary information on hohlraum plasma filling for a variety of NIF vacuum hohlraums. The results show increased filling for smaller hohlraums and/or longer pulses and increased $f_{\text {hot }}$ for higher intensities and more filling. $\mathrm{T}_{\text {hot }}$ 's are consistent with prior hohlraum data.

\section{Acknowledgments}

This work would not have been possible without a large team which includes the NIF operations staff, the Bechtel Nevada LO calibrations staff. This work was performed under the auspices of the U.S. Department of Energy by University of California Lawrence Livermore National Laboratory under Contract No. W-7405-ENG-48.

\section{References}

[1] J.H. Nuckolls, Phys. Today 35(9), 24 (1982)

[2] W.C. Mead, E.K. Stover, R.L. Kauffman, H.N. Kornblum and B.F. Lasinski, Phys. Rev. A 38 , 5275 (1988).

[3] L.J. Suter, R.L. Kauffman, C.B. Darrow, A.A. Hauer, H. Kornblum, O.L. Landen, T.J. Orzechowski, D.W. Phillion, J.L. Porter, L.V. Powers, A. Richard, M.D. Rosen, A.R. Thiessen, and R. Wallace, Phys. Plasmas 3, 2057 (1996)

[4] K.S. Budil, T.S. Perry, and P.M. Bell, J.D. Hares, P.L. Miller, T.A. Peyser, R. Wallace, H. Louis, and D.F. Smith, Rev. Sci. Insrum. 67, 485 (1996)

[5] J.W. McDonald, R.L. Kauffman, J.R. Celeste, M.W. Rhodes, F.D. Lee, L.J. Suter and A.P. Lee, J.M. Foster and G. Slark, Rev. Sci. Instrum. 75, (10) 3753 (2004)

[6] John D. Lindl, Phys. Plasmas 11, 3933 (1995)

[7] J.W. McDonald, et. al. Physics of Plasmas to be published

[8] E.L. Dewald, L.J. Suter, O.L. Landen, et. al. "Radiation-driven hydrodynamics of vacuum hohlraums on the National Ignition Facility" (Physical Review Letters in press) 